\title{
RELEASE OF NORADRENALINE FROM CAT SPLEEN SLICES BY POTASSIUM
}

\author{
A.G. GARCÍA ${ }^{1}$, S.M. KIRPEKAR ${ }^{2}$ \& R. PASCUAL ${ }^{3}$ \\ Departamento de Farmacología, Facultad de Medicina Valladolid, Spain
}

1 When cat spleen slices were exposed to a potassium-enriched $(140 \mathrm{~mm})$ Krebs solution, $367 \pm 31 \mathrm{ng} \mathrm{g}^{-1} 5 \mathrm{~min}^{-1}$ of noradrenaline (NA) was released into the bathing medium.

2 Phenylephrine and clonidine $\left(10^{-7}\right.$ to $\left.10^{-3} \mathrm{M}\right)$ did not significantly modify the potassium-evoked NA release; acetylcholine decreased it in a dose-dependent manner.

3 Phenoxybenzamine increased NA release by $50 \%$ but phentolamine did not alter it; high concentrations of this drug greatly decreased NA release. Cocaine increased the NA release by about $30 \%$.

4 It is suggested that the failure of sympathomimetic amines to depress, and of $\alpha$-adrenoceptor blocking agents to enhance the release of NA by high potassium concentrations may be related to prolonged depolarization of the nerve terminals, which may desensitize presynaptic $\alpha$-receptors. The fact that the same drugs are able to modify NA release during electrical nerve stimulation may be ascribed to the much shorter periods of depolarization occurring under these conditions.

\section{Introduction}

Recent evidence suggests that modulation of adrenergic transmission occurs via adrenoceptors and acetylcholine receptors located on the sympathetic nerve terminals (see Kirpekar, 1975; Starke, Taube \& Borowski, 1977). Most of the supporting evidence for a feed-back mechanism via adrenoceptors has been obtained from experiments in which the release of noradrenaline (NA) was evoked by orthodromic nerve stimulation. NA is also released by prolonged depolarization with potassium (Kirpekar \& Wakade, 1968; García, Kirpekar \& Sanchéz-García, 1976). It seemed of interest to determine whether this type of NA release is also controlled by presynaptic $\alpha$-receptors in a manner comparable to the NA release induced by intermittent electrical stimulation.

\section{Methods}

Cats were anaesthetized with ether, the abdomen was opened by a midline incision and the spleen was

\footnotetext{
${ }^{1}$ Present address: Departamento de Farmacología, Facultad de Medicina Autónoma, Madrid-34, Spain.

${ }^{2}$ Present address: Department of Pharmacology, State University of New York, Downstate Medical Center, Brooklyn, N.Y. 11203, U.S.A.

${ }^{3}$ Present address: Department of Pharmacology, School of Medicine, The Center for the Health Sciences, Los Angeles. California, 90024. U.S.A.
}

quickly removed and placed in a Petri dish containing ice-cold Krebs-Ringer-bicarbonate solution (KB).

\section{Preparation of slices}

Spleens were cut into sections of about $0.5 \mathrm{~mm}$ thickness with a Mcllwain tissue slicer. The slices were washed twice and stored in cold KB for further use. They were then distributed between several beakers, each containing $8 \mathrm{ml}$ of $\mathrm{KB}$ and incubated at $37^{\circ} \mathrm{C}$ in a shaking water bath under an atmosphere of $95 \%$ $\mathrm{O}_{2}$ and $5 \% \mathrm{CO}_{2}$. Each beaker contained about $1 \mathrm{~g}$ spleen tissue. All groups were initially incubated in normal $\mathrm{KB}$ for $30 \mathrm{~min}$ during which the $\mathrm{KB}$ was renewed 3 times.

All drugs were added to normal KB 5 min before stimulation with potassium, and also to the KB containing high concentrations of potassium, to which the tissues were exposed for 5 minutes. To pretreat the slices with phenoxybenzamine $(\mathrm{Pbz})$ they were incubated for $20 \mathrm{~min}$ in $\mathrm{KB}$ containing $\mathrm{Pbz}$ and washed 3 times with fresh KB during the following $10 \mathrm{~min}$ utes. In order to evoke release of NA, the slices were transferred to a beaker containing $8 \mathrm{ml}$ of potassiumenriched (140 mM) KB either in the presence or absence of drugs for a period of 5 minutes. In each experiment one group of slices was used to study the release of NA by potassium in the absence of drugs, and 3-5 other groups were used to study the effects 
of increasing drug concentrations on the potassiumevoked release.

\section{Incubation solutions}

The composition of the normal Krebs-bicarbonate solution (KB) was as follows: (mM) $\mathrm{NaCl} 119, \mathrm{KCl}$ 4.7, $\mathrm{CaCl}_{2} 2.5, \mathrm{MgSO}_{4} 7 \mathrm{H}_{2} \mathrm{O} 1.2, \mathrm{KH}_{2} \mathrm{PO}_{4} 1.1$, $\mathrm{NaHCO}_{3} 25$, glucose 11 and the disodium salt of ethylenediaminetetraacetic acid (EDTA), 0.03. This solution was equilibrated with $95 \% \mathrm{O}_{2}$ and $5 \% \mathrm{CO}_{2}$, and the final $\mathrm{pH}$ was 7.4 to 7.5. Potassium-enriched KB $(140 \mathrm{~mm})$ was prepared by the addition of $\mathrm{K}_{2} \mathrm{SO}_{4}$ and reduction of $\mathrm{NaCl}$ to maintain isotonicity.

\section{Assay of noradrenaline}

At the end of each 5 min incubation period, the incubation media were pipetted off, cooled and immediately acidified with concentrated perchloric acid to a final acid concentration of $0.4 \mathrm{~N}$. Sodium metabisulphite and EDTA were added to a final concentration of $0.1 \%$ and $0.05 \%$, respectively. The samples were then centrifuged and the NA present in the supernatant was determined after purification on alumina according to Shellenberger \& Gordon (1971). The mean recovery of added NA measured in concomitant assays was $80 \%$ and all values were corrected for recovery. In order to calculate the potassium-evoked NA release the amount of NA released spontaneously was subtracted from that released in potassiumenriched $\mathrm{KB}$ and expressed as $\mathrm{ng} / \mathrm{g}$ wet tissue per 5 minutes.

\section{Results}

Effect of $\alpha$-adrenoceptor stimulating drugs on the potassium-evoked noradrenaline release

Exposure of spleen slices to potassium enriched $(140$ $\mathrm{mm}$ ) $\mathrm{KB}$ for $5 \mathrm{~min}$ caused a rise in the NA release by $367 \pm 31 \mathrm{ng} / \mathrm{g}(n=26)$. Addition of phenylephrine to normal KB in increasing concentrations up to $10^{-6} \mathrm{M}$ did not affect the spontaneous release of NA. Phenylephrine in concentrations of $10^{-5}, 10^{-4}$ or $10^{-3} \mathrm{M}$ released $37 \pm 18,92 \pm 36$ and $106 \pm 44 \mathrm{ng}$ NA $\mathrm{g}^{-1} 5 \mathrm{~min}^{-1}$ respectively $(n=4)$. The phenylephrine release was always subtracted from the potassium-evoked release. Figure 1 shows the release of NA evoked by potassium in the presence of phenylephrine. In the concentrations used, phenylephrine did not significantly alter the potassium-induced release of NA.

Clonidine was also tested since this amine has been shown to have a preferential affinity for presynaptic $\alpha$-adrenoceptors. This agent did not consistently

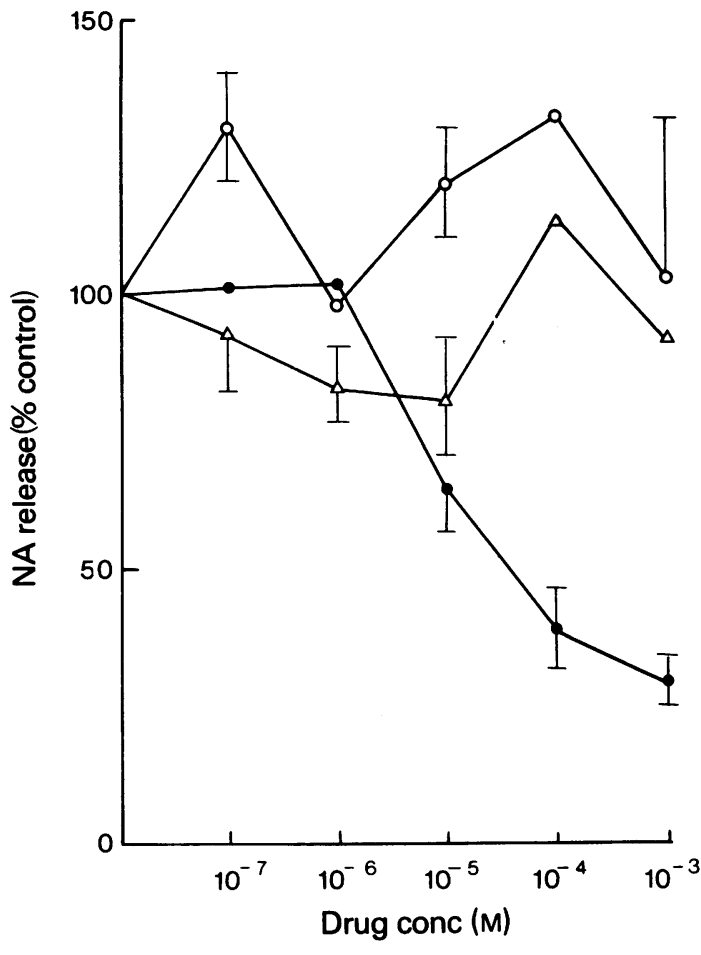

Figure 1 Effect of $\alpha$-adrenoceptor stimulating drugs and of acetylcholine on the release of noradrenaline (NA) evoked by potassium. (O) Clonidine; $(\triangle)$ phenylephrine and (O) acetylcholine. Ordinate scale: increase in the release of NA evoked by 5 min exposure to potassium enriched (140 mM) Krebs solution (KB) (NA released in potassium-rich $K B$ minus NA released in normal KB) expressed as \% of control (release in the absence of drugs). Vertical bars indicate s.e. mean of 4-5 experiments.

change the potassium-evoked NA release, even at a concentration of $10^{-3} \mathrm{M}$ (Figure 1). Clonidine alone had no effect on spontaneous NA release.

Effects of acetylcholine on the release of noradrenaline by high potassium concentrations

Since the $\alpha$-adrenoceptor stimulating drugs had no effect on the release of NA evoked by potassium, we tested a cholinoceptor stimulating drug with muscarinic action to see if it would modify NA release. Four experiments were carried out in which increasing amounts of acetylcholine were added $5 \mathrm{~min}$ before and during stimulation with potassium. Acetylcholine alone did not release NA. Only the highest concentration used $\left(10^{-3} \mathrm{M}\right)$ released $28 \pm 8 \mathrm{ng} \mathrm{NA} \mathrm{g}{ }^{-1} 5$ $\min ^{-1}(n=4)$. Figure 1 shows that acetylcholine did not affect the potassium-evoked NA release at con- 


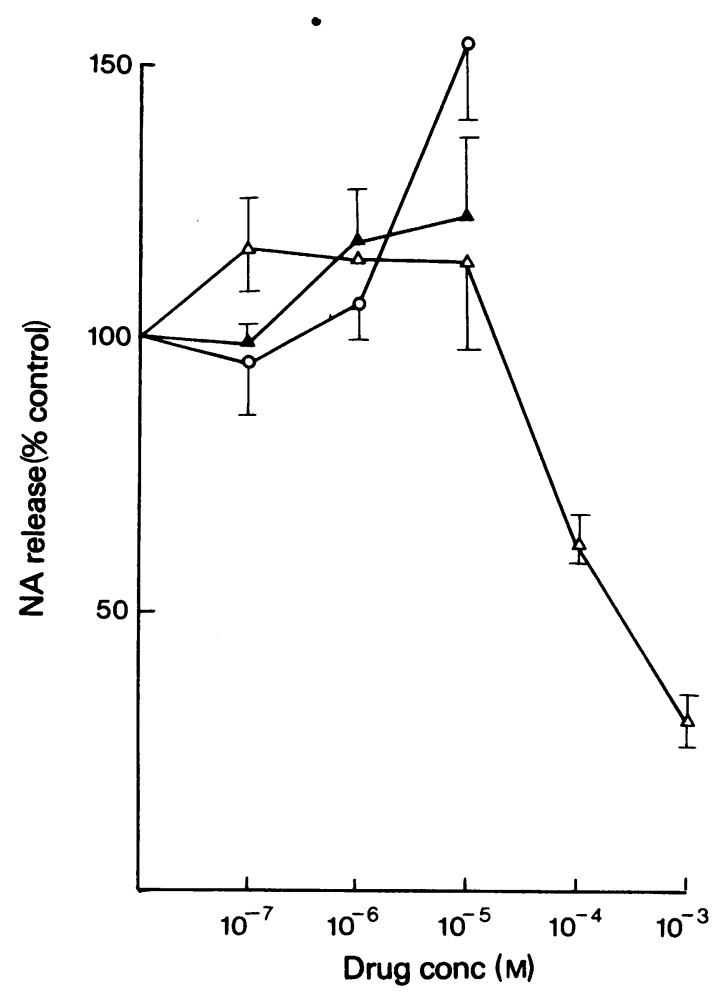

Figure 2 Effect of $\alpha$-adrenoceptor blocking agents and cocaine on the release of noradrenaline (NA) by potassium. (O) Phenoxybenzamine; $(\Delta)$ phentolamine and $(\Delta)$ cocaine. Ordinate scale: increase in the release of NA evoked by $5 \mathrm{~min}$ exposure to potassium enriched (140 $\mathrm{mm}$ ) Krebs solution (KB) (NA released in potassium rich KB minus NA released in normal $K B$ ) expressed as \% control (release in the absence of drug). Vertical bars indicate s.e. mean of 4-5 experiments.

centrations of $10^{-7}$ and $10^{-6} \mathrm{M}$ but it blocked NA release by $35 \%, 61 \%$, and $70 \%$ at $10^{-5}, 10^{-4}$ and $10^{-3}$ concentrations, respectively $(n=5)$.

\section{Effects of $\alpha$-adrenoceptor blocking drugs on potassium-} evoked noradrenaline release

It is well established that phentolamine and $\mathrm{Pbz}$ enhance NA release evoked by nerve stimulation at low frequencies. Two groups of experiments were carried out in which the effects of these drugs on potassium-induced NA release were studied. Figure 2 shows that phentolamine $\left(10^{-7}\right.$ to $\left.10^{-5} \mathrm{M}\right)$ slightly enhanced the potassium-evoked release of NA. The increase was of the order of $15 \%$. Higher concentrations of the drug drastically reduced the release; the inhibition reached $70 \%$ at $10^{-3} \mathrm{M}(P<0.05)$.
$\mathrm{Pbz}\left(10^{-5} \mathrm{M}\right)$ enhanced the potassium-induced release of NA by $50 \%$, but did not modify the NA release at lower concentrations (Figure 2). In an earlier study, Kirpekar \& Wakade (1968) were unable to show unequivocally an enhancing effect of $\mathrm{Pbz}$ on potassium-induced release of NA from the perfused cat spleen. At these high concentrations $\mathrm{Pbz}$ blocks the neuronal uptake of NA. It was therefore of interest to test whether cocaine, a drug which also blocks NA uptake but has no affinity for $\alpha$-adrenoceptors, would affect the release of the transmitter in a similar manner. At the concentrations used, cocaine did not modify spontaneous NA release. Cocaine enhanced potassium-evoked release by 20 and $25 \%$ at $10^{-6}$ and $10^{-5} \mathrm{M}$, respectively but did not enhance the NA release at lower concentrations (see Figure 2). On the basis of this observation we suggest that enhancement of the potassium-induced NA release by $\mathrm{Pbz}$ may be attributed to the ability of this drug to block reuptake of NA.

\section{Discussion}

The ability of $\alpha$-adrenoceptor blocking agents to enhance, and that of exogenous NA and other $\alpha$-adrenoceptor stimulating drugs to inhibit the release of NA in response to electrical nerve stimulation led to the hypothesis that there are presynaptic $\alpha$-adrenoceptors on the adrenergic nerve terminals. The released NA acts on these receptors to cause inhibition of its further release (i.e., negative feedback inhibition). $\alpha$-Adrenoceptor blocking agents, by occupying these receptors, prevent the feedback inhibition and allow a greater amount of NA to be released per nerve impulse (Kirpekar \& Puig, 1971). A negative feedback mechanism mediated by $\alpha$-adrenoceptors at adrenergic terminals has also been suggested by Starke $(1971 ; 1972)$ on the basis of findings on the perfused rabbit heart and by Enero, Langer. Rothlin \& Stefano (1972) on the basis of findings on the isolated nictitating membrane of the cat.

The present experiments have shown that $\alpha$-adrenoceptor blocking agents did not enhance and $\alpha$-adrenoceptor stimulating drugs did not inhibit the release of NA from cat isolated spleen slices caused by high potassium concentrations. In contrast, NA release from the spleen induced by intermittent electrical stimulation of sympathetic nerves was inhibited by $\alpha$-adrenoceptor stimulating drugs, such as phenylephrine and clonidine (Kirpekar, Furchgott, Wakade $\&$ Prat, 1973). Recently it has also been reported that $\left[{ }^{3} \mathrm{H}\right]$-NA release from the rat vas deferens by high potassium concentrations $(80 \mathrm{mM})$ was not appreciably affected by exogenous NA or phentolamine (Wakade \& Wakade, 1977).

Starke \& Montel (1974) showed that the $\alpha$-adreno- 
ceptor stimulating drug, oximetazoline, depressed NA release evoked by potassium $(50 \mathrm{mM})$ from the perfused rabbit heart. However, at their supramaximal concentration of $10^{-5} \mathrm{M}$, oxymetazoline reduced the overflow of the transmitter only by $40 \%$. On the other hand, when a potassium concentration of $80 \mathrm{~mm}$ was used, the release of NA was not changed by oxymetazoline. The authors concluded that released NA and exogenous $\alpha$-adrenoceptor stimulating drugs induce a common inhibitory mechanism, which is saturated when the NA concentration in the biophase is high (i.e., when a high frequency of nerve stimulation or very high potassium concentrations are used).

Our experiments raise some doubts about the interpretation of Starke \& Montel: first, even very high concentrations (up to $10^{-3} \mathrm{M}$ ) of clonidine and phenylephrine did not affect potassium-evoked release. Since clonidine at extremely low concentrations blocks the nerve-evoked release (Starke \& Altman, 1973; Starke, Montel, Gayk \& Merker, 1974; Idowu \& Zar, 1976), this drug must have a very high affinity for presynaptic $\alpha$-adrenoceptors and should therefore be able to compete succesfully with NA in the occupation of these receptors. We do not know the concentration of the released NA in the biophase, but it is unlikely that this is greater than $10^{-3} \mathrm{M}$. Second, phentolamine and $\mathrm{Pbz}$ were ineffective in enhancing potassium-induced NA release. Even though the $\alpha$-adrenoceptor blocking agent, $\mathrm{Pbz}$, enhanced the release of NA by $50 \%$, this increase, like that produced by cocaine, can be attributed to the ability of this agent to block the reuptake of NA into the sympathetic nerves (Gillespie \& Kirpekar, 1965). Since Pbz blocks the adrenoceptors irreversibly, a competition between Pbz and NA at the receptor level seems highly unlikely.

On the other hand, acetylcholine did inhibit the NA release induced by high potassium concentrations. Dubey, Muscholl \& Pfeiffer (1975) have recently shown that the release of NA by solutions containing potassium in high concentrations from the perfused rabbit heart was also blocked by the cho-

\section{References}

DUBEY, M.P., MUSCHOLL, E. \& PFEIFFER, A. (1975). Muscarinic inhibition of potassium-induced noradrenaline release and its dependence on the calcium concentration. Naunyn-Schmiedebergs Arch. Pharmac., 291, $1-15$.

ENERO, M.A., LANGER, S.Z., ROTHLIN, R.P. \& STEFANO, F.J.E. (1972). Role of the $\alpha$-adrenoceptor in regulating noradrenaline overflow by nerve stimulation. $\mathrm{Br}$. J. Pharmac., 44, 672-688.

GARCIA, A.G., KIRPEKAR, S.M. \& SANCHEZ-GARCIA, P. (1976). Release of noradrenaline from the cat spleen by nerve stimulation and potassium. J. Physiol., Lond., 261, 301-317. linoceptor stimulating drug, methacholine. In addition, lowering the calcium concentration in the solution potentiated the inhibitory effects of methacholine. They concluded that activation of muscarinic receptors at the terminal adrenergic fibre decreases the availability of calcium for transmitter release. A similar proposal was also advanced to explain the fact that the inhibition by acetylcholine of the release of NA was much more pronounced at low than at high stimulation frequencies of sympathetic nerves (Kirpekar, Prat \& Wakade, 1975).

The failure of sympathomimetic amines to inhibit the release of NA induced by high potassium concentration, as compared to their effectiveness against NA release induced by intermittent electrical nerve stimulation, may suggest that when depolarization of the sympathetic terminal is complete and prolonged the so-called presynaptic $\alpha$-receptors become desensitized and no longer modulate transmitter release. A similar situation may arise when nerves are stimulated at very high frequencies (see Starke, Endo \& Taube, 1975). On the basis of these observations we would like to propose that failure of sympathomimetic amines to depress NA release by high potassium concentrations may be related to the length of time the nerve membrane remains depolarized. Nerve stimulation causes short-lived periods of nerve membrane depolarization; and as the frequency of nerve stimulation increases, the length of time the membrane is depolarized also increases; high potassium may represent the extreme case in which the membrane remains depolarized for the duration of potassium application. If the ability of sympathomimetic drugs to inhibit the release of NA is diminished at higher frequencies, then it is not surprising that they also fail to depress output of NA by high potassium.

This work was supported by a grant from the 'Fondo Nacional para el Desarrollo de la Investigación Científica', Presidencia del Gobierno, Madrid, Spain. S.M.K. was a recipient of Josiah Macy Jr Foundation fellowship. We are grateful to G.P. Nicolás for expert technical assistance.

GILLESPIE, J.S. \& KIRPEKAR, S.M. (1965). The inactivation of infused noradrenaline by the cat spleen. J. Physiol., Lond., 176, 205-227.

IDOWU, O.A. \& ZAR, M.A. (1976). Inhibitory effect of clonidine on a peripheral adrenergic synapse. Br. J. Pharmac., 58, 278P.

KIRPEKAR, S.M. (1975). Factors influencing transmission at adrenergic synapses. Prog. Neurobiol., 4, 163-210.

KIRPEKAR, S.M. FURCHGOTT, R.F., WAKADE, A.R. \& PRAT, J.C. (1973). Inhibition by sympathomimetic amines of the release of norepinephrine evoked by nerve stimulation in the cat spleen. J. Pharmac. exp. Ther., 187, 529-538. 
KIRPEKAR, S.M., PRAT. J.C. \& WAKADE. A.R. (1975). Effect of calcium on the relationship between frequency of stimulation and release of noradrenaline from the perfused spleen of the cat. Naunyn-Schmiedebergs Arch. Pharmac., 287, 205-212.

KIRPEKAR, S.M. \& PUIG, M. (1971). Effect of flow-stop on noradrenaline release from normal spleens and spleens treated with cocaine, phentolamine or phenoxybenzamine. Br. J. Pharmac., 43, 359-369.

KIRPEKAR, S.M. \& WAKADE, A.R. (1968). Release of noradrenaline from the cat spleen by potassium. J. Physiol., Lond., 194, 595-608.

SHELLENBERGER, M.K. \& GORDON, J.H. (1971). A rapid simplified procedure for simultaneous assay of norepinephrine, dopamine, and 5-hydroxytryptamine from discrete brain areas. Analyt. Biochem., 39, 356-372.

STARKE, K. (1971). Influence of $\alpha$-receptor stimulants on noradrenaline release. Naturwissenschaften, 58, 420.

STARKE, K. (1972). Alpha sympathomimetic inhibition of adrenergic and cholinergic transmission in the rabbit heart. Naunyn-Schmiedebergs Arch. Pharmac., 274, 18-45.

.STARKE, K. \& ALTMANN, K.P. (1973). Inhibition of adrenergic neurotransmission by clonidine: an action on prejunctional $\alpha$-receptors. Neuropharmac., 12 , 339-347.

STARKE, K. ENDO, T. \& TAUBE, H.D. (1975). Relative preand postsynaptic potencies of $\alpha$-adrenoceptor agonists in the rabbit pulmonary artery. Naunyn-Schmiedebergs Arch. Pharmac., 291, 55-78.

STARKE, K. \& MONTEL, H. (1974). Influence of drugs with affinity for $\alpha$-adrenoceptors on noradrenaline release by potassium, tyramine and dimethylphenylpiperazinium. Eur. J. Pharmac., 27, 273-280.

STARKE, K., MONTEL, H., GAYK, W. \& MERKER, R. (1974). Comparison of the effects of clonidine on pre- and postsynaptic adrenoceptors in the rabbit pulmonary artery. Alpha-sympathomimetic inhibition of neurogenic vasoconstriction. Naunyn-Schmiedebergs Arch. Pharmac., 285, 133-150.

STARKE, K., TAUBE, H.D. \& BOROWSKI, E. (1977). Presynaptic receptor systems in catecholaminergic transmission. Biochem. Pharmac., 26, 259-268.

WAKADE. A.R. \& WAKADE, T. (1977). Factors controlling the output of norepinephrine from the rat vas deferens. Fedn Proc., 36, 327.

(Received May 9, 1977. Revised July 5, 1977.) 